\title{
Mental Health of the Oldest Old: The Relevance of Centenarian Studies to Psychogeriatric Research
}

The dramatic and unexpected increase in life expectancy observed over the past few decades in Western countries is undoubtedly one of the great medicosocial achievements of this century. These gains have principally been made at higher ages and are reflected in the proliferation of centenarians. In France, the estimated number of centenarians was 200 in 1953 , around 3,000 at the present time, and 6,000 projected for the end of the century. Similar trends are observed in the United Kingdom; the Royal Secretary sent messages of congratulations on behalf of the Queen to 300 centenarians in 1955 and to 3,300 in 1987. In parallel with these demographic observations, research on centenarians is becoming increasingly widespread with clinical and general population studies now having been conducted in France, Hungary, Japan, Italy, Finland, Denmark, the United States, and China. A database on mortality trends in the oldest old has been established by Vaino Kannisto and Roger Thatcher at the Center for Research on Aging, Odense University Medical School, providing validated data on centenarians from 12 Western European countries and Japan since 1950. Additionally, the Danish centenarian register established by Bernard Jeune contains data on centenarians back to the 1700 s.

From these data, Jeune (1995) and Kannisto (1988) have concluded that despite a plethora of literary references to centenarians across the centuries, centerians are apparently a relatively recent phenomenon. According to their extensive analyses, there were probably no centenarians before 1800 , and since 1950 the increase in prevalence is exponential in developed countries, doubling every 10 years. This has largely been due to a drop in mortality at the highest age ranges such that centenarians are not only more numerous today, but are also living longer. We thus see in the latter part of this century the appearance of the supercentenarians, aged between 105 and 110 years.

Centenarians have a certain curiosity value, and like great sportsmen they mark the limits of human achievement. Research on the health and social status of the oldest old is also linked to an important debate in the area of public health concerning the quality of the life years being gained by the human species. Gruenberg (1977) has warned of "the failures of success"; that is, that advances in medical technology are significantly reducing mortality but not disease incidence, leading to significant increases in disease prevalence. Similarly, reviewing the results of consecutive mental health surveys in the United States, Kramer (1980) has predicted a "coming pandemic of mental disorders and their related disabilities." In terms of health policy, this may lead us to question whether extended life at the end of the Gompertz curve is really worth 
having and whether quality rather than quantity of life should be given priority in the allocation of health resources. Research on healthy centenarians may also contribute to the knowledge of the etiology of mental illness. As survivors, their biological characteristics may contain important clues to understanding the disease processes to which fellow members of their generation have succumbed at younger ages: for example, protective genetic mechanisms against neurodegenerative disease.

A number of preliminary findings relating to the health of centenarians have been published suggesting above all that they are a highly heterogeneous group. On the one hand, cognitive impairment is common, most typically taking the form of preserved awareness, intact conversational skills accompanied by diminished ability to learn new skills, and mild bradyphrenia and bradykinesia with normal response latency (Powell, 1994). It is difficult, however, for cognitive assessment to take into account the destructive effects of social isolation (especially where this is accompanied by sensory impairment). My own experience (Ritchie, 1997) has been that the stimulating effect of repeated cognitive assessment and social contact that goes beyond the usual "Hallo dear, how's your health today?" may significantly increase cognitive performance within a short time period.

Dementia prevalence in centenarians has been estimated at around $50 \%$ (Allard, 1991; Ivan, 1990), which is slightly higher than the $45 \%$ estimated by our meta-analysis (Ritchie \& Kildea, 1995), but these studies have used nonrepresentative samples and brief screening instruments inappropriate for persons with severe sensory deficits. Autopsy studies show that although cognitive decline may be common and cortical atrophy extensive, a clear histopathological distinction can be made between normal aging and dementia (Hauw et al., 1986), supporting our own research findings that the senile dementias are unlikely to be a continuation of the normal aging process (Ritchie, in press; Ritchie \& Kildea, 1995).

Physical disability is not surprisingly also frequent among centenarians, with assistance being required by one third of centenarians to eat, a half to go to the toilet, two thirds to get dressed, and a half who have bad eyesight (Allard, 1991; Fürjes, 1990). On the other hand, many centenarians have a lifestyle considered normal for young adults, with the French survey showing that in the past year $2 \%$ had visited a foreign country, and in the past month $17 \%$ had traveled to another part of France and $6 \%$ had used public transport. From studies of successive cohorts, mortality in centenarians also appears to be declining and their overall health to be improving, with many indicators of the aging process appearing to slow down (Kannisto, 1993; Svanborg et al., 1984). Above all, the French study found that two thirds of French centenarians rated their quality of life as good or very good (Allard, 1991).

Centenarian research is obviously raising a number of interesting hypotheses related to the aging process. In particular, the question of what is "normal" and "optimal" mental health in the very old is important in deciding whether palliative care or active intervention should be provided. Unfortunately, research to date has been conducted on small samples usually biased toward well individuals who are able to participate, or institutionalized elderly who are easy to locate. In the area of mental health, the tests and procedures used have generally 
had poor validity and are mostly inappropriate for use with the very old. Welldesigned research programs are clearly called for, and the report presented by Dr. Silver and colleagues in this issue provides an important contribution by examining the relationship between anatomical changes and cognitive performance in centenarians. This project has also carefully evaluated testing procedures and the problems involved in assessing the oldest old.

\section{REFERENCES}

Allard, M. (1991). A la recherche du secret des centenaires [In search of the secret of the centenarians]. Paris: Le Cherche-Midi.

Fürjes, E. (1990). Ophthalmological examinations of centenarians. In E. Beregi (Ed.), Centenarians in Hungary (pp. 65-82). Basel, Switzerland: Karger.

Gruenberg, E. M. (1977). The failures of success. The Milbank Memorial Fund Quarterly, 55, 3-24.

Hauw, J.-J., Vignolo, P., Duykaerts, C., Beck, M., Forette, F., et al. (1986). Etude neuropathologique de 12 centenaires [Neuropathological study of 12 centenarians]. Revue Neurologique, 142, 107-115.

Ivan, L. (1990). Neuropsychiatric examination of centenarians. In E. Beregi (Ed.), Centenarians in Hungary (pp. 53-64). Basel, Switzerland: Karger.

Jeune, B. (1995). In search of the first centenarians. In B. Jeune \& J. Kannisto (Eds.), Exceptional longevity: From prehistory to the present (pp. 11-24) [Odense Monographs on Population Aging, no. 2]. Odense, Denmark: Odense University Press.

Kannisto, V. (1993). La mortalité des centenaires en baisse [Mortality in centenarians is falling]. Population, 4, 1070-1072.

Kannisto, V. (1988). On the survival of centenarians and the span of life. Population Studies, 42, 389-406.

Kramer, M. (1980). The rising pandemic of mental disorders and associated chronic diseases and disabilities. Acta Psychiatrica Scandinavica, 62(Suppl. 285), 282-297.

Powell, A. L. (1994). Senile dementia of extreme aging-A common disorder of centenarians. Dementia, 5, 106-109.

Ritchie, K. (1997). Eugeria, longevity and normal ageing. British Journal of Psychiatry, $171,501$.

Ritchie, K. (in press). Is Alzheimer's disease just old age? In J. Growdon \& M. Rossor (Eds.), Bluebooks of practical neurology. Newton, MA: Butterworth-Heinemann.

Ritchie, K., \& Kildea, D. (1995). Is senile dementia age-related or ageing-related? Evidence from a meta-analysis of dementia prevalence in the oldest old. Lancet, 346, 931-934.

Svanborg, A., Berg, S., Nilsson, L., \& Persson, G. (1984). A cohort comparison of functional ability and mental disorders in two representative samples of 70 year olds. In ]. Wertheimer \& M. Marois (Eds.), Senile dementia (pp. 405-409). New York: Alan R Liss.

Karen Ritchie, MPsych, PhD INSERM Montpellier, France 